MATEC Web of Conferences 33, 03007 (2015)

DOI: $10.1051 /$ matecconf/ 20153303007

(C) Owned by the authors, published by EDP Sciences, 2015

\title{
Effects of HSHPT on the martensitic transformation behaviour of an NiTi alloy
}

\author{
Carmela Gurau ${ }^{1}$, Gheorghe Gurau ${ }^{1, a}$, V Sampath ${ }^{2}$ and Viorica Musat ${ }^{1}$ \\ ${ }^{1}$ Faculty of Engineering "Dunarea de jos "University of Galati, Domneasca Street, No. 111, 800201, Galati, Romania \\ ${ }^{2}$ Department of Metallurgical and Materials Engineering, Indian Institute of Technology Madras, Chennai-600 036, India
}

\begin{abstract}
High speed high pressure torsion (HSHPT) is a novel severe plastic deformation technique that is used to produce bulk ultrafine-grained nickel-titanium shape memory alloys. In this study, the effect of grain refinement on phase transformation was investigated in a near equiatomic NiTi shape memory alloy subjected to processing by this technique. Phase transformations involving different degrees of deformation and stability of thermally-induced phase transformations were analyzed by differential scanning calorimetry (DSC). The measurements suggest that the martensitic transformation occurred even when the highest degree of deformation was applied. Optical microscopy $(\mathrm{OM})$, scanning electron microscopy (SEM) and transmission electron microscopy (TEM) investigations bring to light that the true strain applied controls the evolution of the microstructure. The results are presented and discussed in detail in this paper.
\end{abstract}

\section{Introduction}

Although NiTi-based alloys have numerous characteristics that are in common with other shape memory alloys (SMAs), such as superelasticity, shape memory effect, two-way shape memory effect, etc., they have certain unique characteristics, such as low elastic anisotropy, one of the reasons for their incredibly high ductility [1], that are different from them. As the most popular functional material with excellent mechanical properties and functional fatigue resistance they have captivated the attentions of the researchers in recent times $[2,3]$. Due to their properties, such as fast response to temperature changes, narrow hysteresis, corrosion resistance and biocompatibility, near equiatomic NiTi alloys are a very promising candidate for myriad practical applications in medicine and engineering [4-8].

The functional properties of NiTi are sensitive to microstructure, and refinement of grain size represents a processing path to significant upgradation of the functional properties of recoverable strain and recovery stress [9].

The functional stability, one of the main characteristics of SMAs, is determined by a change in their martensitic and austenitic transformation temperatures. Several factors may lead to improved and stable shape memory behavior. Since many of these being intrinsic material properties they are not amenable for change without completely changing the character of the materials [10]. Maximizing the strength of the austenitic phase has been found to be a factor that is favorable for increasing the stability of many alloy systems, which can be achieved more easily by the current metallurgical processes $[11,12]$. These processes, among others, include the well-known methods: alloying, precipitation hardening and thermomechanical treatments. Severe plastic deformation processes followed by post deformation annealing are the kind of thermomechanical treatments that are used to obtain functional stability.

Within the last few years, several promising severe plastic deformation (SPD) processing methods have been developed to produce bulk nanostructured or ultrafine grained materials with their grain size in the range of $100-1000 \mathrm{~nm}$ considering the future potential industrial applications of nanotechnology [13-15]. In recent times, high pressure torsion (HPT) has received considerable attention from researchers considering that it is an SPD method that permits significant grain refinement, without the concomitant cracking involved in processing [16-19]. The samples used in HPT are mostly in the form of discs, small upright cylinders, rings or annulus. The specimen is subjected to a high hydrostatic pressure (usually in range of 1-10 GPa) accompanied by torsional straining between two heavy punches. The reduction in grain size takes places accompanied by an increase in the density of dislocations disposed into equilibrium sub-grains or nonequilibrium grain boundaries [16, 20].

The aim of the present paper is to use new HSHPT process, a derivative of HPT process, to fabricate large disc springs with ultrafine and nanocrystalline microstructure and enhanced stability using NiTi alloys. HSHPT process involves torsional deformation coupled with high pressure as in classical HPT. The major

\footnotetext{
${ }^{\mathrm{a}}$ Corresponding author: gheorghe.gurau@ugal.ro
} 
difference lies in the fact that in HSHPT the sample gets heated up due to the heat generated by friction between alloy and high speed of rotation of the superior punch. The HSHPT process draws on the synergistic effect of grain size reduction, matrix hardening of the parent phase and precipitation strengthening. It therefore emerges as an attractive method to enhance the mechanical and physical properties of materials to a significant level [20].

\section{Materials and methods}

A NiTi alloy with 50.3 at.\% of $\mathrm{Ni}$ and 49.7 at.\% of $\mathrm{Ti}$ was selected for the study and was procured from Memory-Metalle GmbH, Germany. The as-received Nirich alloy was in the hot extruded condition. The HSHPT research studies were initiated on air cooled extruded wires of $9 \mathrm{~mm}$ diameter. Samples were cut from the extruded wires and subjected to logarithmic strain levels of $1.24,1.38,1.52,1.63,2.52$ and 2.82 by HSHPT. The details of HSHPT machine and the method that was used in the present studies were reported earlier [21]. The SPD disc springs were obtained after giving different amounts/degrees of deformation achieving up to $45 \mathrm{~mm}$ in diameter with the thickness varying between 1.21 and $0.17 \mathrm{~mm}$. The extent of deformation strain was estimated using a logarithmic relationship [22].

Specimens were prepared for microstructural examinations by optical (OM), scanning electron microscopy (SEM) as well as transmission electron microscopy (TEM). The billets diametrically cut and embedded into cold mounting resin were prepared adopting standard metallographic practice. This was followed by etching them using a solution of $10 \mathrm{vol} . \%$ of $\mathrm{HF}, 45$ vol. $\%$ of $\mathrm{HNO}_{3}$ and 45 vol. $\%$ of $\mathrm{H}_{2} \mathrm{O}$. The optical microscopic observations were carried out using an OLIMPUS BX51 microscope equipped with a video camera and QCapture software. A Zeiss microscope equipped with an energy dispersive X-ray spectroscope (EDX) was used for the SEM examination. Microstructural examinations were first carried out on hot extruded alloy specimens and on billets subjected to HSHPT processing to varied levels of deformation. The microstructural examinations were intended to throw light on the microstructural brought about to the austenitic hot-rolled NiTi alloy by the compressive and torsional forces introduced during processing by HSHPT.

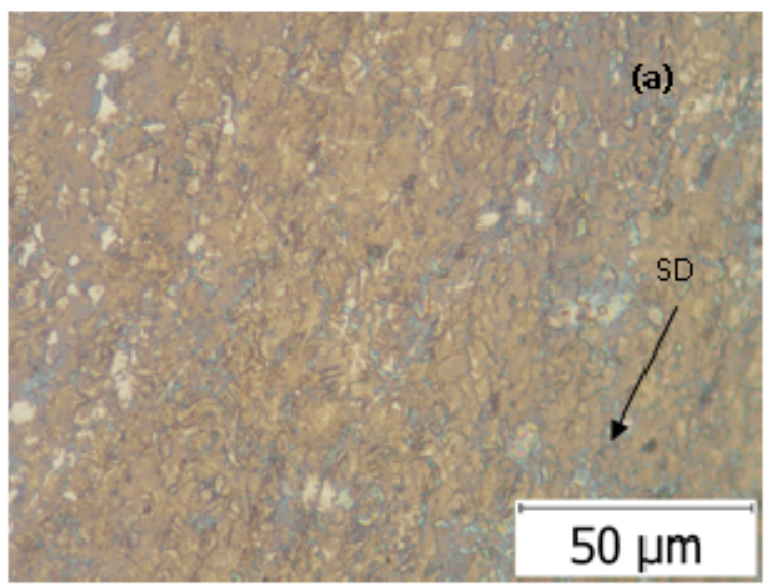

For a much deeper examination of the microstructure the specimen that was subjected to a deformation level of 1.63 was analyzed by transmission electron microscopy (TEM). The microstructural analysis of the samples by TEM was carried out using a Tecnai 20G2 TEM equipped with EDX facility operating at a voltage of 200 $\mathrm{kV}$. Thin foils from extruded and HSHPT processed specimens were prepared using an electrolyte with $90 \%$ by vol. of methanol and $10 \%$ by vol. of perchloric acid. The transformation temperatures of the specimens processed to contain different degrees of deformation were determined by differential scanning calorimetry (DSC TA Q20). A heating/cooling rate of $10^{\circ} \mathrm{C} / \mathrm{min}$ in the range of -40 to $80^{\circ} \mathrm{C}$ was adopted for the experiments. The HSHPT parameters were selected using an EATON SVX024A1-4A1B1 frequency converter via PLC XC 200 . The rotational speed of the upper punch was selected at $1795 \mathrm{rpm}$. The maximum torsional moment was 60.7 $\mathrm{Nm}$. The pressure level, recorded with a Hottinger Spider 8 equipment, was at $2.0277 \mathrm{GPa}$.

\section{Results and discussion}

The HSHPT technique, which evolved from the conventional HPT, offers the advantage of reducing the crystallite size down to the nanocrystaline range, enables production of discs, whose diameter ranged from $20 \mathrm{~mm}$ to $45 \mathrm{~mm}$. The major difference between classic HPT and high speed HPT lies in the high rotational speed of the superior punch (1795 rpm), which causes slippage and thereby intense friction between the sample and the anvils. It induces refinement of grains size, although the temperature in the sample rises from room temperature up to $\sim 800^{\circ} \mathrm{C}$. The heating takes place in the whole of the sample in less than 2 seconds and entire severe plastic deformation step occurs rapidly within 11-28 s in the case of the Ni-rich alloy.

Figure 1 shows the optical micrographs indicating the microstructures across the cross-section of $\mathrm{Ni}$-Ti samples subjected to different degrees of deformation by HSHPT processing.

In the case of the sample that has undergone a logarithmic strain of 1.38 , the grains manifest the apparent deformation and have a certain orientation along with shear direction that seems to depict the deformation texture. Plenty of substructures occurs inside the grains,

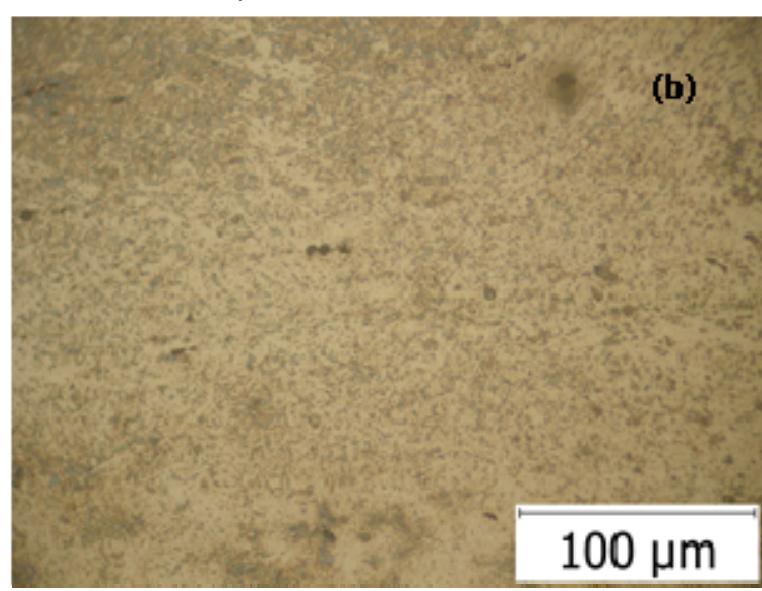

Figure 1. OM of the NiTi after severe plastic deformation by HSHPT logarithmic strain 1.38 (a) and 2.52 (b). 
too. With a further increase in the plastic deformation (at a logarithmic strain of 2.52), the grains become ambiguous or are no longer be able to be observed. It takes place the marked coagulation of the precipitates.

For a better understanding of the morphological changes caused by HSHPT processing on structure, SEM examinations were carried out. The micrographs are shown in Fig. 2. In the case of the smallest degree of plastic deformation applied to the alloy in this study (logarithmic strain of 1.24), the grains size decreased. The microstructure was characterized by extensive twins, numerous substructural features in several different orientations within the grains. The microstructure resulting from a logarithmic strain of 1.51 shows preferred orientation of fine twins and variant structure. The coarse precipitate particles formed due to coagulation are more easily visible under the scanning electron microscope.

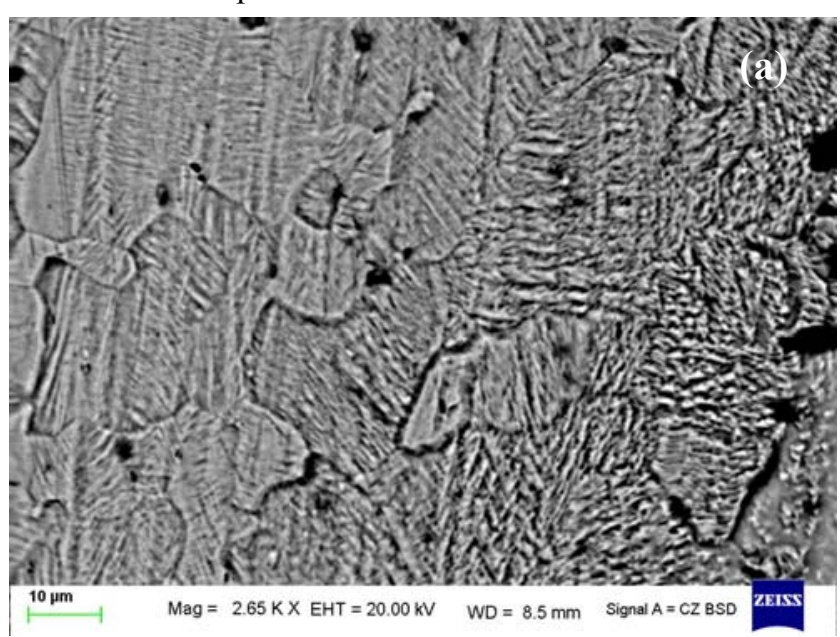

Fig. 3(a) shows a heavily deformed area of the HSHPT processed disc incorporating a logarithmic strain of 1.63. The images highlight essentially B2 austenite grains containing abundance of lattice defects, mainly dislocations. Dislocations accumulate in clusters, dislocation tangles and parallel dislocation lines and show a dark contrast [28].

The presence of high density dislocations can be observed on boundaries and within the grains too. They act as obstacles for dislocation slip, leading to their pileup. Fig. 3(b) shows numerous grain boundaries that are straight, a lot of sub-grain contrast, stress fields and a few twins. In Fig. 3(c), the representative twin morphology is clearly visible apart from convoluted strain contrast. Most of the grain boundaries are faceted. The stress-induced martensite twins with their size in the range of 50-70 nm occur inside the large area of the sample. The finer lamellar and variant structure are preferentially

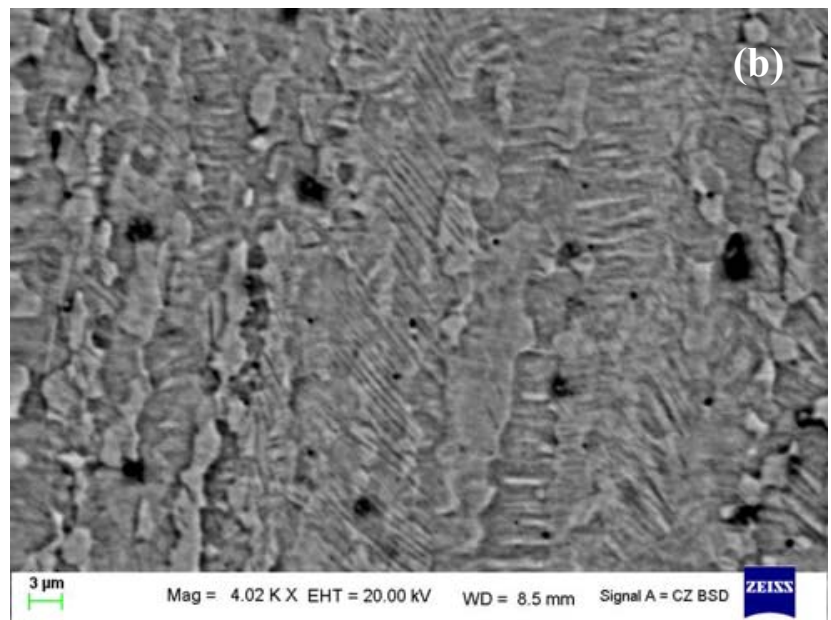

Figure 2. SEM of the NiTi after severe plastic deformation by HSHPT logarithmic strain of 1.24 (a) and 1.51 (b)

Inside the nanocrystalline or nanocrystallineamorphous B2 NiTi matrix fabricated by SPD methods the precipitate phase formed is usually $\mathrm{Ni}_{4} \mathrm{Ti}_{3}$ due to saturation of nickel in the phase. In previous research work $[23,24,25]$ performed on nearly equiatomic NiTi alloys, $\mathrm{NiTi}_{2}$ precipitate particles with a cubic crystal structure, were reported to have been formed when the alloys were subjected to annealing at $400^{\circ} \mathrm{C}$ following heavy cold rolling. The EDX study on HSHPT samples confirmed the presence of $\mathrm{NiTi}_{2}$ or $\mathrm{Ni}_{2} \mathrm{Ti}_{4} \mathrm{O}$, while at the same time there was this conspicuous absence of lenticular-shaped $\mathrm{Ni}_{4} \mathrm{Ti}_{3}$. Most of the precipitate particles with a dark contrast are composed of 55.59 at.\% of $\mathrm{Ti}$ and 44.41 at. $\%$ of $\mathrm{Ni}$.

Fig. 3 shows the bright-field TEM micrographs of the severely deformed alloy. The images were taken at room temperature from the shear plane.

Combining high hydrostatic compression with rotation leads to large grain refinement suppressing thereby the initiation and growth of cracks and increasing plasticity. The specimen subjected to HSHPT processing contains austenite with equiaxed structural elements, which are specific to HPT process followed by post deformation annealing (PDA) [26, 27]. The amorphous bands that are specific to HPT no longer appear after this type of severe plastic deformation. orientation resemble to $<011>$ Type II twins [29]. An important role of grain refinement that occurs during severe plastic deformation is to act as martensitic twin boundaries, being implied on impeding the motion of dislocations.

Enlarged bright-field TEM micrographs highlight microstructural morphology of twins of the sample subjected to HSHPT processing (Fig. 3(d)). The twins in range of $120 \mathrm{~nm}$ are in the proximity of a coagulated second phase, which is rich in carbon, and where a high density of dislocations appears accompanied by a complex deformation. A more detailed TEM view of the HSHPT processed sample in Fig. 4(a) reveals the presence of twinning and serrated grains boundaries. This type of grain boundaries is interpreted as indications for non-equilibrium, which is manifested by the non-uniform shape between two adjoining grain boundaries [20]. The serrated grain boundaries are usually observed in materials after severe plastic deformation.

In Fig. 4(b) are presented the TEM micrograph and the corresponding selected area diffraction pattern of the HSHPT processed disc which has undergone a logarithmic deformation of 1.63. Multiple fine martensite variants with random orientations together with precipitate particles can also be seen. 

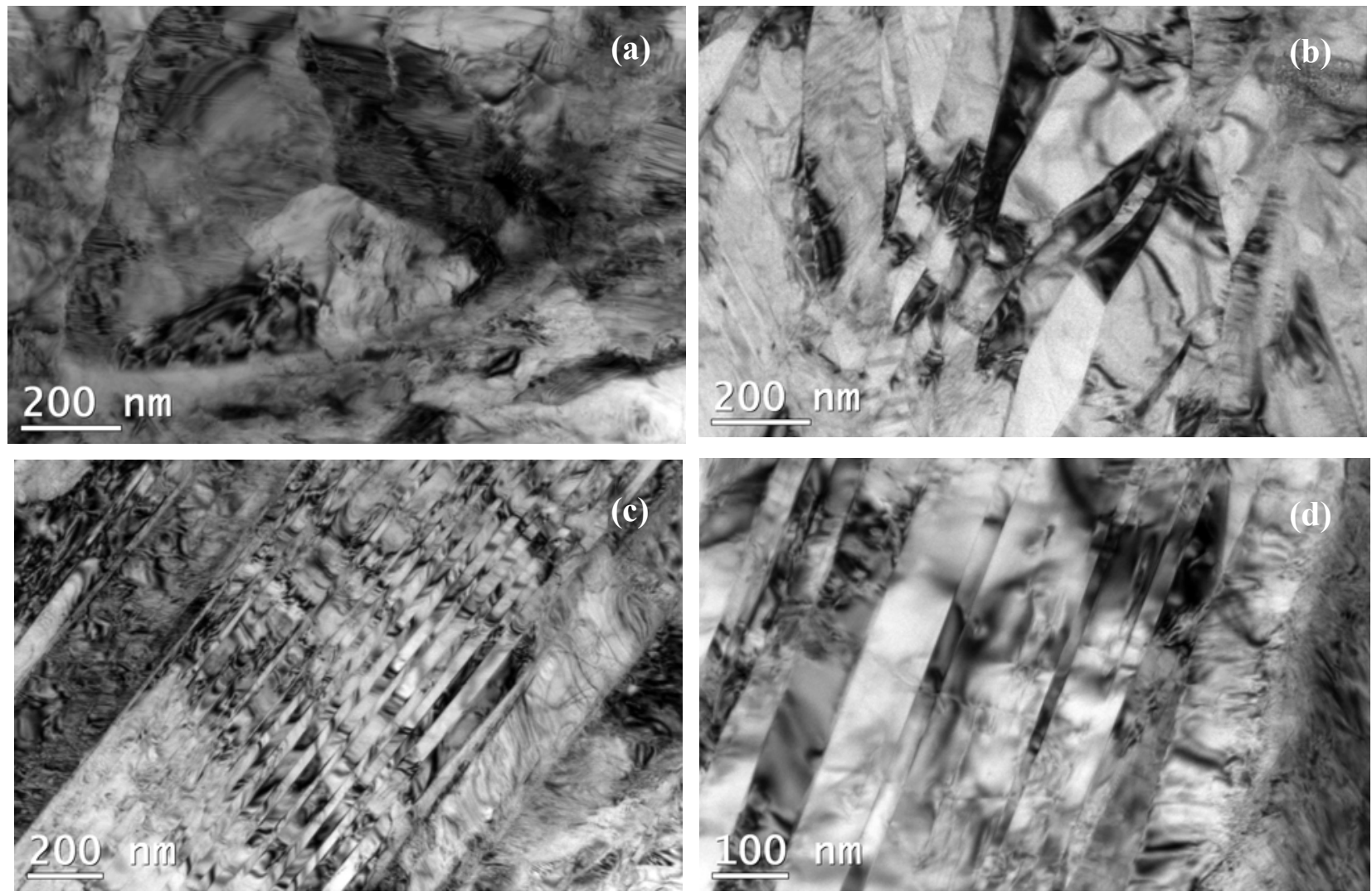

Figure 3. Bright field TEM images of NiTi alloy after HSHPT processing to a logarithmic strain of 1.63.

The present authors point out that the use of novel HSHPT technique, which is a derivative of the classic HPT process, leads to the formation of an ultrafinegrained (UFG) structure in the case of copper- and ironbased SMAs also [21, 30]. The materials processed by severe plastic deformation (SPD) contain a very high density of dislocations. But based on the results of transmission electron microscopy (TEM) of the material processed by us using HSHPT, we can affirm that this specific aspect was conspicuous by its absence. The HSHPT process combines SPD of the billet at room temperature with high pressure torsion followed by PDA.
The diffraction patterns indicated the HSHPT specimens were crystalline, unaccompanied of amorphous region.

Transformation characteristic of transformation for the HSHPT sample processed with 1.24, 1.37 and 1.51 are shown in Fig. 5. The expected emergence of the two step transformation $\mathrm{B} 2 \rightarrow \mathrm{R}^{\prime} \rightarrow \mathrm{B} 19^{\prime}$ on cooling after classic HPT process with the studied composition of NiTi alloy is not present.

The DSC curves exhibit just one strong transformation stage $\mathrm{B} 2^{\prime} \rightarrow \mathrm{B}^{\prime} 9^{\prime}$ that may corresponds to the reducing of the internal stress in the recrystallized
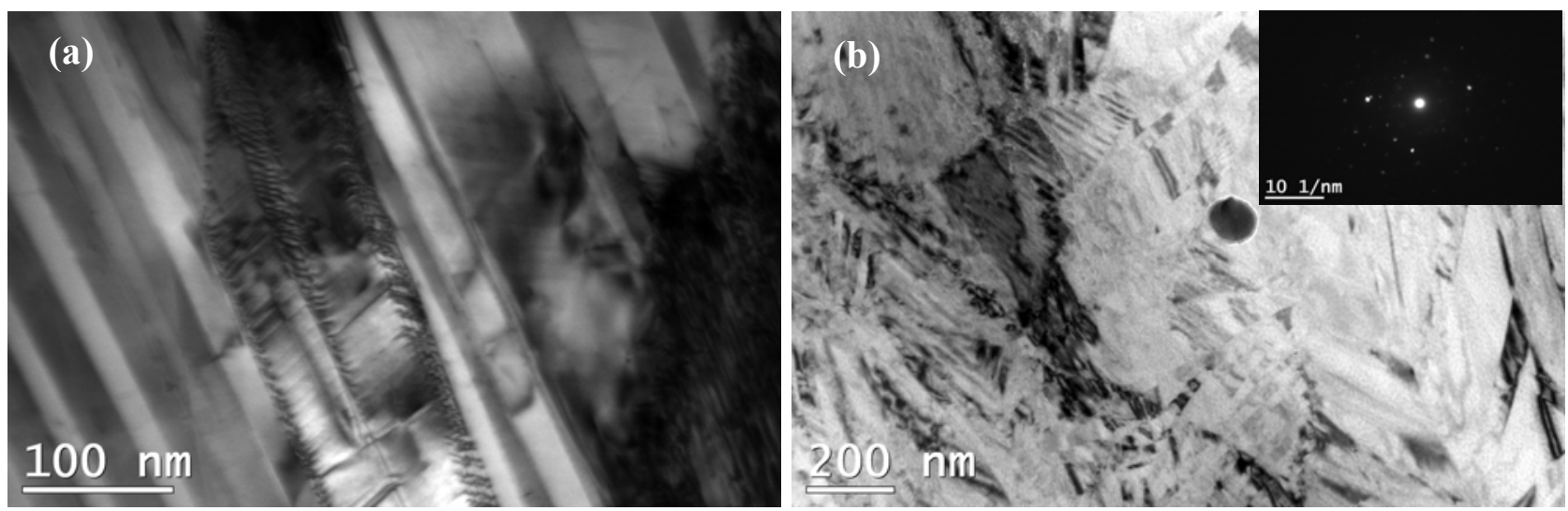

Figure 4. TEM images of NiTi alloy after HSHPT processing to a logarithmic strain of 1.63 (a) and (b). Inset of b: the corresponding diffraction patterns. 


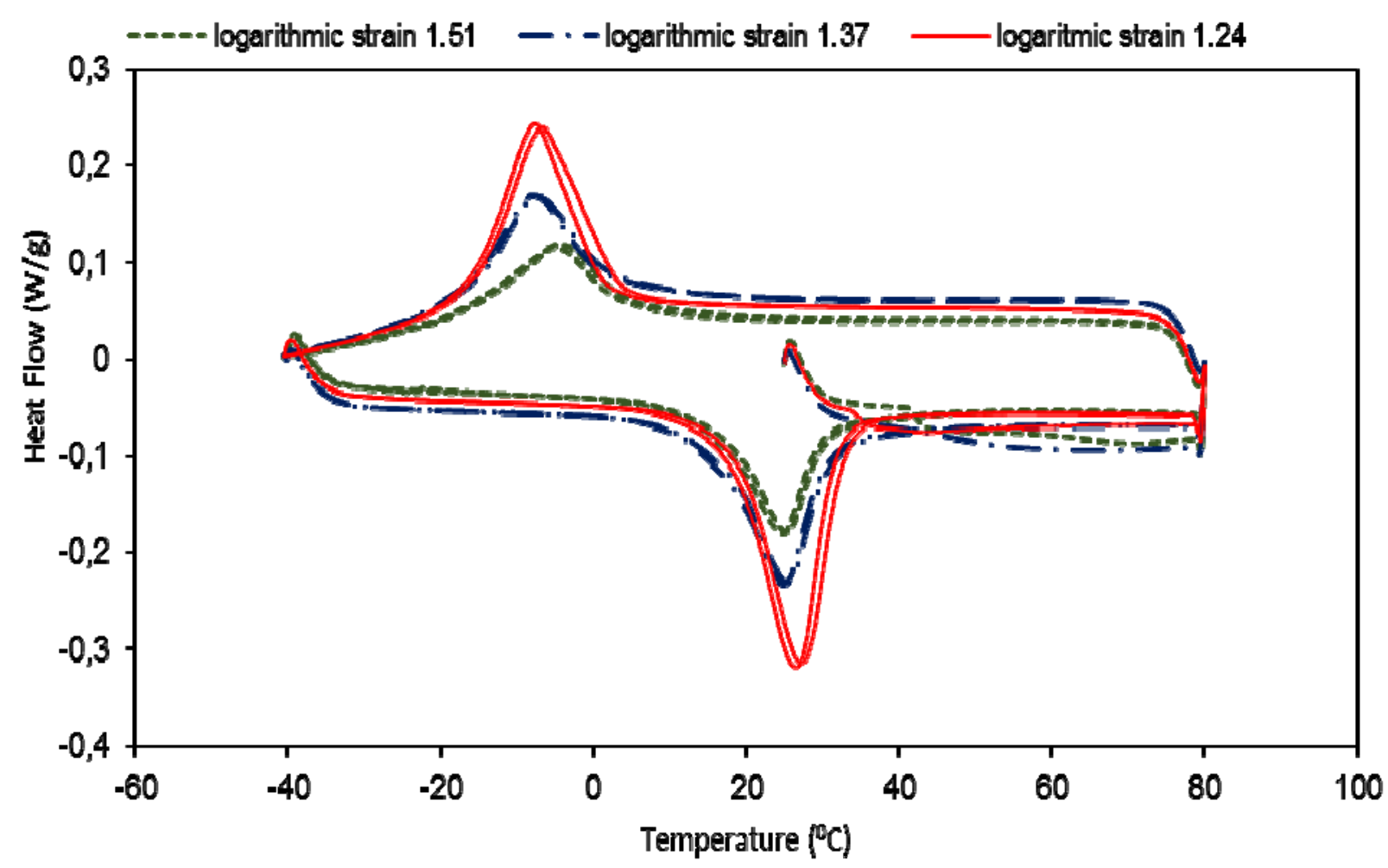

Figure 5. DSC plots for HSHPT'ed NiTi alloy.

grains occurring during the HSHPT process. The transformation temperatures of the severely plastic deformed alloy were determined by the tangent method using maxima of the derivative heat flow curve on the second DSC cycle.

The DSC curves represent a continuous slightly decrease in $\mathrm{M}_{\mathrm{f}}, \mathrm{A}_{\mathrm{s}}, \mathrm{A}_{\mathrm{f}}$ at the increasing the degree of deformation. The decrease in $\mathrm{M}_{\mathrm{s}}$ may be a consequence of depletion of matrix with accumulation of precipitates. The observed trend is in agreement with the established alloy behavior that with an increasing degree of deformation, a decreasing in transformation temperature takes place [6].

The transformation temperatures and the related latent heat of phase transformation for various deformation degree accumulated by HSHPT are given in Table 1 .

The temperature $T_{0}$ represents the equilibrium temperature between martensitic and austenite phases. $\mathrm{T}_{0}$ can be expressed by the following relationship [31-33]:

$$
\mathrm{T}_{0}=0.5\left(\mathrm{M}_{\mathrm{s}}-\mathrm{M}_{\mathrm{f}}\right)
$$

It can also be expressed by:

$$
\mathrm{T}_{0}=\Delta \mathrm{H}^{\mathrm{M} \rightarrow \mathrm{A}} / \Delta \mathrm{S}^{\mathrm{M} \rightarrow \mathrm{A}}[32]
$$

where: $\Delta \mathrm{H}^{\mathrm{M} \rightarrow \mathrm{A}}$ refers to the entalpy change, $\Delta \mathrm{S}^{\mathrm{M} \rightarrow \mathrm{A}}$ refers to the entropy change.

$\mathrm{G}_{\mathrm{e}}$ is the elastic energy associated with selfaccommodated martensitic variants and may be calculated by the following relationship:

$$
\mathrm{G}_{\mathrm{e}}=\left(\mathrm{M}_{\mathrm{s}}-\mathrm{M}_{\mathrm{f}}\right) \Delta \mathrm{S}^{\mathrm{M} \rightarrow \mathrm{A}}[33]
$$

The variation of $\mathrm{T}_{0}$ and $\mathrm{Ge}$ with the degree of deformation induced by HSHPT is given in Figure 6 .

As seen in Table 1 and Figure 6 the elastic strain energy decreases with the degree of deformation imparted by HSHPT from $17.5 \mathrm{~J}$ to $15.6 \mathrm{~J}$.

Table 1. Effect of degree of severe plastic deformation on the thermodynamic parameters of the alloy

\begin{tabular}{cccccccccc}
\hline $\begin{array}{c}\text { Logarithmic } \\
\text { strain }\end{array}$ & $\mathrm{M}_{\mathrm{f}}\left({ }^{0} \mathrm{C}\right)$ & $\mathrm{M}_{\mathrm{s}}\left({ }^{0} \mathrm{C}\right)$ & $\mathrm{A}_{\mathrm{s}}\left({ }^{0} \mathrm{C}\right)$ & $\mathrm{A}_{\mathrm{f}}\left({ }^{0} \mathrm{C}\right)$ & $\mathrm{T}_{0}\left({ }^{0} \mathrm{C}\right)$ & $\Delta \mathrm{H}^{\mathrm{M} \rightarrow \mathrm{A}}(\mathrm{kJ} / \mathrm{kg})$ & $\Delta \mathrm{S}^{\mathrm{M} \rightarrow \mathrm{A}}(\mathrm{J} / \mathrm{kg} . \mathrm{K})$ & $\begin{array}{c}\text { Thermal } \\
\mathrm{G}_{\mathrm{e}}(\mathrm{J})\end{array}$ & $\begin{array}{c}\text { hysteresis } \\
\left(\mathrm{A}_{\mathrm{f}}-\mathrm{M}_{\mathrm{s}}\right) \\
\left({ }^{\circ} \mathrm{C}\right)\end{array}$ \\
\hline 1.24 & -16.5 & 1.29 & 17.64 & 31.68 & 16.485 & 16.19 & 0.98 & 17.5 & 30.39 \\
1.37 & -18.89 & 1.97 & 15.25 & 30.83 & 16.4 & 12.58 & 0.77 & 16.0 & 28.86 \\
1.51 & -23.1 & 4.16 & 15.16 & 30.42 & 17.29 & 9.9 & 0.57 & 15.6 & 26.26 \\
\hline
\end{tabular}


The equilibrium temperature of the martensitic and austenite phase decreases slightly for logarithmic strain of 1.37 , and then again increases to $\sim 17.29^{\circ} \mathrm{C}$ for $\mathrm{a}$ logarithmic strain of 1.51 .

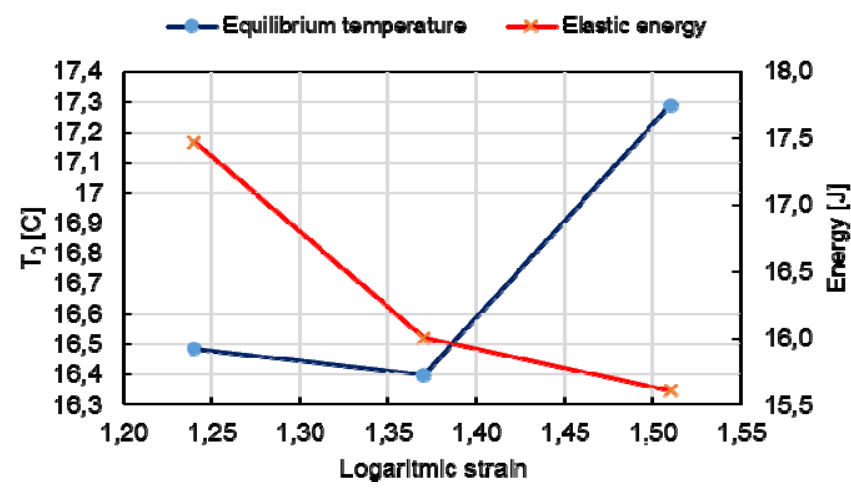

Figure 6. Effect of severe plastic deformation on the equilibrium temperature $T_{0}$ and $\mathrm{G}_{e}$ energy

\section{Conclusions}

SPD processing by HSHPT technique leads to significant grain refinement in a nickel-rich $\mathrm{Ni}$ - $\mathrm{Ti}$ shape memory alloy. The HSHPT process combines severe plastic deformation (SPD) applied on the sample at room temperature by high pressure torsion with PDA imparted due to the heat generated by friction between the sample and punches. Depending on the degree of deformation imparted the stress-induced martensite twins are in the ultrafine grained $(\leq 200 \mathrm{~nm})$ or nanocrystalline $(50-70$ $\mathrm{nm}$ ) range. The grain refinement and moderate density of lattice defects promote the martensitic transformation marked by one strong peak ex post deformation annealing. The amorphous bands that are characteristic of SPD are missing. The distorted structure modified the nature of the martensitic transformation leading to lower transformation temperatures and better shape memory effect.

\section{Acknowledgements}

This research work was supported by the Project PN.IIPT-PCCA-2011-3.1-0174, Contract 144/2012. We would like to gratefully acknowledge the help rendered by Department of Metallurgical and Materials Engineering, Indian Institute of Technology Madras, Chennai in the investigations.

\section{References}

1. K. Otsuka, X. Ren, Progr. Mat. Sci. 50, 511 (2005)

2. X. Wang, B. Verlinden, J.V. Humbeeck, Intermet. 62, 43 (2015)

3. X. Wang, S. Kustov, K.Li, D. Schryvers, B. Verlinden, Acta Mat. 82, 224 (2015)
4. K.C. Atli, R.D. Noebe, A. Garg, Y.I. Chumlyakov, I.V. Kireeva, Acta Mat. 59, 4747 (2011)

5. Y. Kaynak, H. Tobe, R.D. Noebe, H.E. Karaca, I.S. Jawahir, Scripta Mat. 74, 60, (2014)

6. H. Sahmir, M.N. Ahmadabadi, C.T. Wang, J.M. Jung, H.S. Kim, T.G. Langdon, Mat. Sci. Eng. A 629, 16 (2015)

7. A. Evirgen, I. Karaman, J. Pons, R.D. Noebe, Acta Mat. 83, 48 (2015)

8. E.Mohammad Sharifi, A. Kermanpur, F Karimzadeh, Mat.Sci.Eng. A598, 183 (2014)

9. A. Kreicberg, V. Brailovski, S. Prokoshkin, D. Gunderov, M. Khomutov, Mat.Sci.Eng. A622, 21 (2015)

10. J.V. Humbeeck, J.Phys.IV France, C4, 01 (1991)

11. E. Hornbogen, J.Mater.Sci. 39, 385 (2004)

12. K.C. Atli, I. Karaman, R.D. Noebe, H.J. Maier, Scripta Mat. 64, 315 (2011)

13. R.Z. Valiev, Mater.Sci.Eng. A59, 234 (1997)

14. V.M.Segal, Mater.Sci.Eng. A197, 157 (1995)

15. J.P. Mathieu, S. Suwas, A. Eberhardt, L.S. Toth, P. Moll, J.Mat.Proc.Tech. 173, 29 (2006)

16. R. Vafaei, M.R. Toroghinejad, R. Pippan, Mat.Sci.Eng. A536, 73 (2012)

17. E. Schaefler, M.B. Kerber, Mat.Sci.Eng. A462, 139 (2007)

18. Y. Harai, K. Edalti, Z. Horita, T.G. Langdon, Acta Mat. 57, 1147 (2009)

19. M. Hafok, R. Pippan, Scripta Mat. 56, 757 (2007)

20. X. Sauvage, G. Wilde, S.V. Divinski. Z. Horita, R.Z. Valiev, Mat.Sci.Eng. A540, 1 (2012)

21. G. Gurău, C. Gurău, O. Potecașu, P. Alexandru, L.G. Bujoreanu, J. Mater. Eng. Perform. 23, 2396 (2014)

22. A.P. Zhilyaev, T.G. Langdon, Prog. Mater. Sci., 53, 893-979, 2008

23. A.R. Pelton, J. DiCello, S. Miyazaki, Minim. Invas. Ther. Allied.Technol 9, 107 (2000)

24. A.K. Srivastava, D. Schryvers, J.Van Humbeeck, Intermet.15, 1538 (2007)

25. M. Karimazadeh, M.R. Aboutalebi, M.T. Salehi, S.M. Abbasi, M. Morakabati, J. All. Comp. 637, $171(2015)$

26. B. Kockar, I. Karaman, A. Kulkarni, Y. Chumlyakov, I.V. Kireeva, J. Nuclear Mat., 361, 298-305, (2007)

27. A. Evirgen, I. Karaman, R. Santamarta, J. Pons, R.D. Noebe, Acta Mat. 83, 48-60, (2015)

28. D. Vojtech, A. Michalcova, J Capek, I Marek, L. Dragounova, Intermet. 49, 7 (2014)

29. K.Tsuchiya, M. Inuzuka, D. Tomus, A. Hosokawa, H. Nakayama, K. Morii, Y. Tokada, M. Umemoto, Mat.Sci.Eng. A438-440, 643 (2006)

30. C. Gurau, G. Gurau, V.Sampath, V. Musat, D.J.N.B. in press (2015)

31. S. Nevin Balo, N. Sel, Termoch.Acta, 536, 1 (2012)

32. C. Tatar, Thermochim.Acta, 437, 121 (2005)

33. Y. Huo, X. Zu, Continuum Mech.Thermodyn. 10, 179 (1998) 